\title{
Management of Intracranial Complications of Sinusitis
}

\author{
Khaled Khamassi', Madiha Mahfoudhi2 ${ }^{*}$, Ayoub Ben Yahia1, Nour Ben Moussa1, \\ Nawel Halila1, Adnen Boubaker', Lobna Bougacha', Rim Lahiani', Mamia Ben Salah' \\ ${ }^{1}$ Department of Otorhinolaryngology-Head and Neck Surgery, Charles Nicolle Hospital, Tunis, Tunisia \\ ${ }^{2}$ Department of Internal Medicine A, Charles Nicolle Hospital, Tunis, Tunisia \\ ${ }^{3}$ Department of Neurosurgery, National Institute of Neurosurgery, Tunis, Tunisia \\ Email: "
}

Received 16 April 2015; accepted 7 June 2015; published 10 June 2015

Copyright (C) 2015 by authors and Scientific Research Publishing Inc.

This work is licensed under the Creative Commons Attribution International License (CC BY).

http://creativecommons.org/licenses/by/4.0/

(c) (i) Open Access

\begin{abstract}
Intracranial complications of sinusitis are rare. However, they have an important morbidity and mortality rate, and can be a source of disabling neurological sequelae in the absence of a rapid diagnosis and adequate treatment. We carry a retrospective study of 23 patients having sinusitis with intracranial complications, treated between 1996 and 2011. All patients underwent complete ENT and neurological examination, biological investigations and sinonasal and cerebral CT. An intraveinous large-spectrum antibiotherapy was administered to all patients. Twenty patients underwent surgery. It included evacuation of the intracranial collection, sinus drainage, with or without cranialization of the frontal sinus. Evolution was assessed on clinical biological and radiological criteria. Mean age was 25 years and sex-ratio was 3.6. Neurological signs were the most frequent symptoms. Rhinological signs were essentially purulent rhinorrhea (14 cases) and nasal obstruction (12 cases). Nasal endoscopy showed pus in the middle meatus in 10 cases. On CT, intracranial complications included subdural empyema (11 cases), extradural empyema (7 cases) and brain abscess ( 5 cases). Associated cerebral thrombophlebitis was noted in 4 cases. Three patients with extradural empyema had had an exclusive medical treatment. All other patients (20 cases) were operated. Clinical and radiological evolution was favorable after initial treatment in 14 cases $(60.8 \%)$. Six patients required secondary surgery. Two patients have died despite intensive care. The intracranial complications of sinusitis are serious and source of important morbidity and mortality. Management should rapid and adequate, combining effective antibiotic therapy and eventually neurosurgical treatment.
\end{abstract}

\section{Keywords}

Sinusitis, Intracranial, Headache, Computed Tomography, Empyema, Abscess, Antibiotics, Drainage, Cranialization

\footnotetext{
"Corresponding author.
}

How to cite this paper: Khamassi, K., Mahfoudhi, M., Yahia, A.B., Moussa, N.B., Halila, N., Boubaker, A., Bougacha, L., Lahiani, R. and Salah, M.B. (2015) Management of Intracranial Complications of Sinusitis. Open Journal of Clinical Diagnostics, 5, 86-95. http://dx.doi.org/10.4236/ojcd.2015.52016 


\section{Introduction}

Intracranial complications of sinus infections are rare (3\% - 11\% of patients with sinusitis), but are also source life-threatening and debilitating neurological complications [1]. They include extra and subdural empyemas, abscesses, meningitis and thrombophlebitis. The infection can spread to the endocranium by contiguity from a frontal, ethmoidal or sphenoidal osteitis or osteomyelitis. It can also spread through retrograde septic thrombophlebitis in the diploic veins, favored by the absence of valves. Another manner for dissemination is the septic emboli which migrate by hematologic way [1].

These complications have an important morbidity and mortality rate, and can be a source of disabling neurological sequelae in the absence of a rapid diagnosis and adequate treatment.

The purpose of this study is to report our results on management of intracranial complications of sinusitis, and through a literature review, to precise the clinical and paraclinical features and to propose an adequate management for this pathology.

\section{Materials and Methods}

This is a retrospective study of 23 patients having sinusitis with intracranial complications, treated between 1996 and 2011. Patients having rhino-cerebral mucormycosis were excluded from this study.

All patients underwent complete ENT and neurological examination, biological investigations (Blood cell count, C-reactive protein, pre-anesthetic investigations). Sinonasal and cerebral computed tomography (CT) was performed in all cases.

An intraveinous large-spectrum antibiotherapy was administered to all patients. Molecules used were thirdgeneration cephalosporins (cefotaxime, ceftazidime), anti-staphylococcals (fosfomycin, vancomycin), fluoroquinolones (ciprofloxacin), aminoglycosides (gentamicin, amikacin) and metronidazole. Its total duration ranged from 6 to 10 weeks. Anticonvulsants (phenobarbital, clonazepam) and heparin were associated respectively in 10 and 4 cases.

Twentypatients underwent surgery. It included evacuation of the intracranial collection, sinus drainage, with or without cranialization of the frontal sinus.

Evolution was assessed on clinical criteria (regression of neurological and rhinologic signs and of the infectious syndrome), and also on biological and radiological criteria. Mean follow-up period was 26 months.

\section{Results}

Average age was 25 years (8 - 62 years) with over $80 \%$ of patients younger than 30 years. Sex-ratio was 3.6. Three patients had a history of head injury (including 2 cases of frontal bone fracture). Two patients had type 1 diabetes. Socio-demographic data are summarized in Table 1.

Seventeen patients had fever. Neurological signs were the most presenting symptoms. Headache was present in all cases, isolated or associated with signs of intracranial hypertension such as vomiting (11 cases). Five patients had seizures and 8 had impaired consciousness. A frontal syndrome was found in 5 cases. Meningeal syndrome has been objectified in 3 cases. Frontal tumefaction was noted in 8 patients (Figure 1). Rhinologic signs were essentially purulent rhinorrhea (14 cases) and nasal obstruction (12 cases). Nasal endoscopy showed pus in the middle meatus in 10 cases. Ophthalmologic examination revealed swelling of the eyelids (7 cases), swelling of the inner corner of the eye (4 cases), exophtalmia (3 cases), ophthalmoplegia (2 cases) and chemosis (2 cases). A decrease in visual acuity was observed in one patient and papilledema in fundoscopy in another patient.

Laboratory tests showed hyperneutrophilia in 16 patients and a high C-reactive protein (CRP) in all cases. Pus sampling with bacteriological examination was positive in 6 cases. The germs were Streptococcus (3 cases), Staphylococcus aureus (2 cases) and Pseudomonas aeruginosa (1 case). Clinical and laboratory tests data are summarized in Table 2.

Sinonasal CT revealed a total or partial fronto-ethmoidal filling in all cases, associated with filling of the sphenoid sinus in 4 cases. Osteitis of the frontal sinus was noted in 13 cases, the posterior table was involved in 3 cases, the anterior in 2 cases and the both in 8 cases (Figure 2). A subperiostal abscess or "Pott's puffy tumor" was noted in 8 patients (Figure 3). Orbital complications were essentially pre or retro-septal cellulitis (2 cases), subperiosteal abscess (2 cases) and orbital abscess (2 cases). Intracranial complications included subdural empyema (11 cases), extradural empyema (7 cases) and brain abscess (5 cases) (Figures 4-6). Associated cerebral 
Table 1. Socio-demograpahic data.

\begin{tabular}{|c|c|}
\hline Mean-age & 25 years ( 8 - 62 years) \\
\hline Sex-ratio & 3.6 \\
\hline $\begin{array}{l}\text { Past medical history } \\
\text { Head injury } \\
\text { Diabetes } \\
\text { Sinonasal surgery }\end{array}$ & $\begin{array}{l}3 \text { cases } \\
1 \text { case } \\
-\end{array}$ \\
\hline Physical examination & Number of cases \\
\hline Fever & 17 \\
\hline $\begin{array}{c}\text { Neurological } \\
\text { headache } \\
\text { vomiting } \\
\text { consciousness disorders } \\
\text { frontal syndrome } \\
\text { seizures } \\
\text { meningeal syndrome }\end{array}$ & $\begin{array}{c}23 \\
11 \\
8 \\
5 \\
5 \\
3\end{array}$ \\
\hline $\begin{array}{l}\text { Rhinologic } \\
\text { purulent rhinorrhea } \\
\text { nasal obstruction } \\
\text { pus in the middle meatus }\end{array}$ & $\begin{array}{l}14 \\
12 \\
10\end{array}$ \\
\hline $\begin{array}{c}\text { Face } \\
\text { frontal tumefaction }\end{array}$ & 8 \\
\hline $\begin{array}{c}\text { Ophtalmologic } \\
\text { Eyelids swelling } \\
\text { Eye inner corner swelling } \\
\text { exophtalmia } \\
\text { ophtalmoplegia } \\
\text { chemosis } \\
\text { decrease in visual acuity } \\
\text { papilledema }\end{array}$ & $\begin{array}{l}7 \\
4 \\
3 \\
2 \\
2 \\
1 \\
1\end{array}$ \\
\hline Laboratory tests data & \\
\hline $\begin{array}{c}\text { High CRP } \\
\text { Hyperneutrophilia } \\
\text { Positive bacteriology }\end{array}$ & $\begin{array}{c}23 \\
16 \\
6\end{array}$ \\
\hline
\end{tabular}

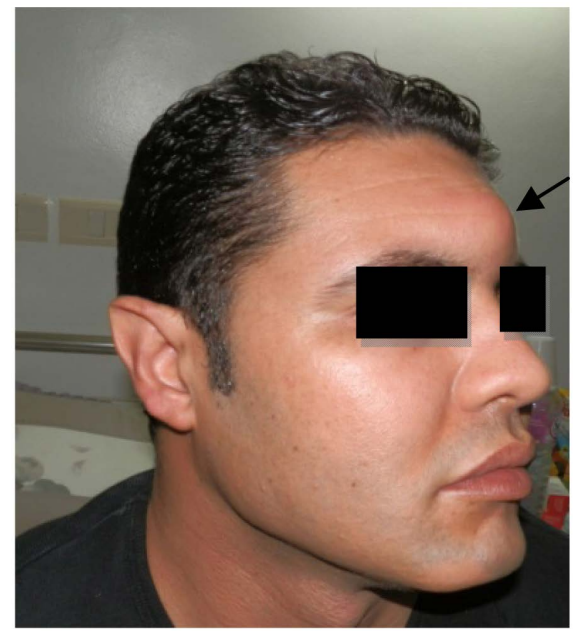

Figure 1. Frontal tumefaction. 


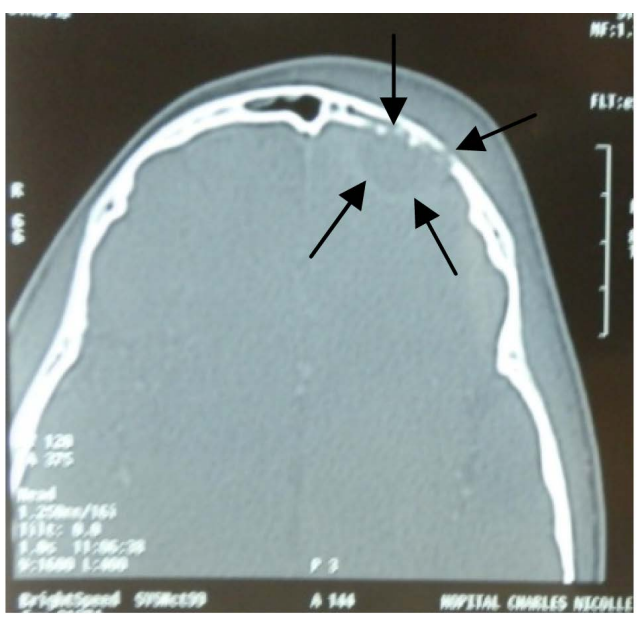

Figure 2. (Axial CT): Frontal osteitis with subdural empyema.

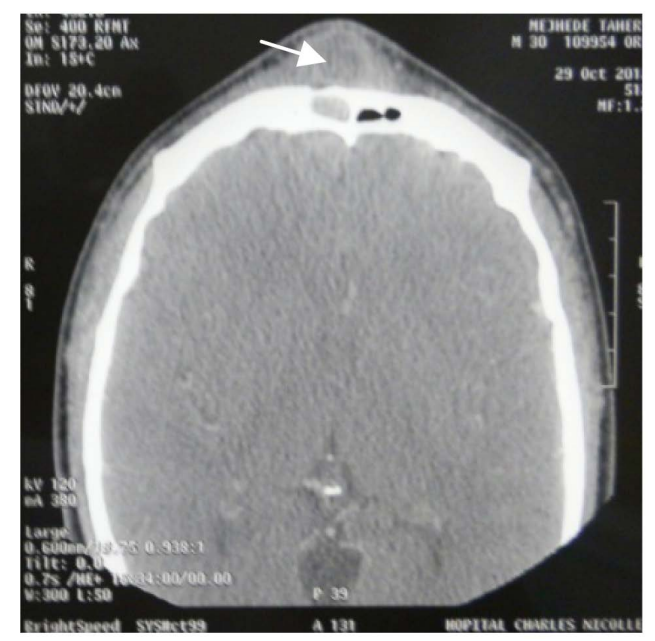

Figure 3. (Axial CT): Pott’s puffy tumor.

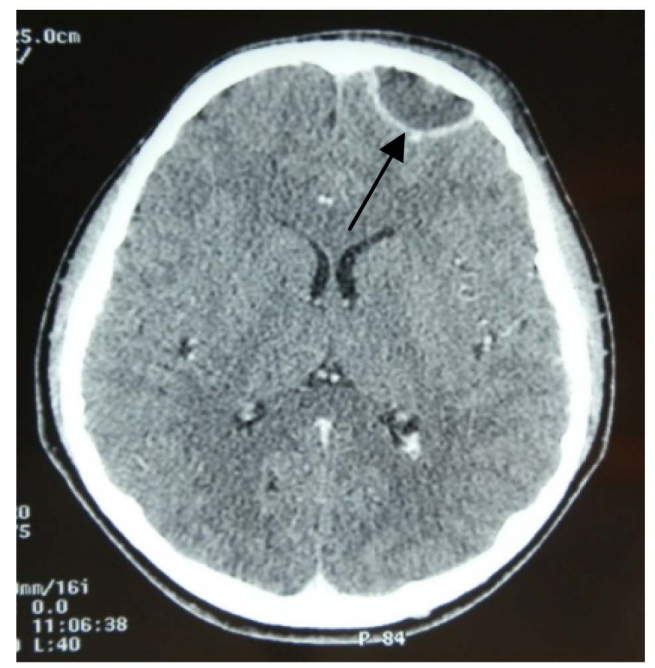

Figure 4. (Axial CT): Extradural empyema of the frontal lobe. 


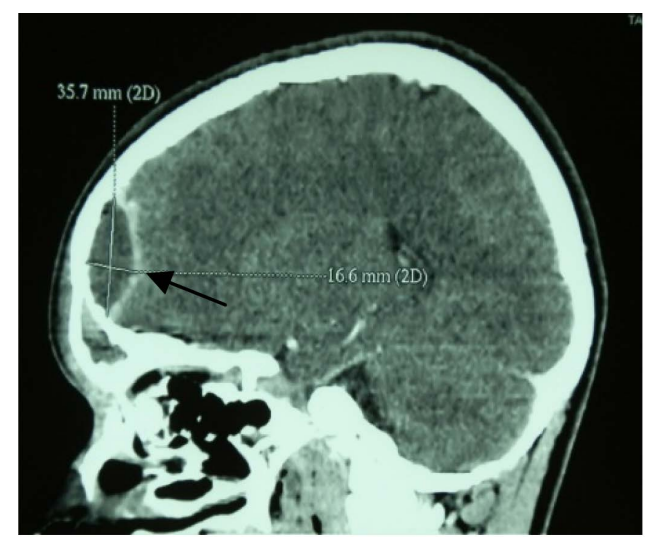

Figure 5. (Sagittal CT): Extradural empyema of the frontal lobe.

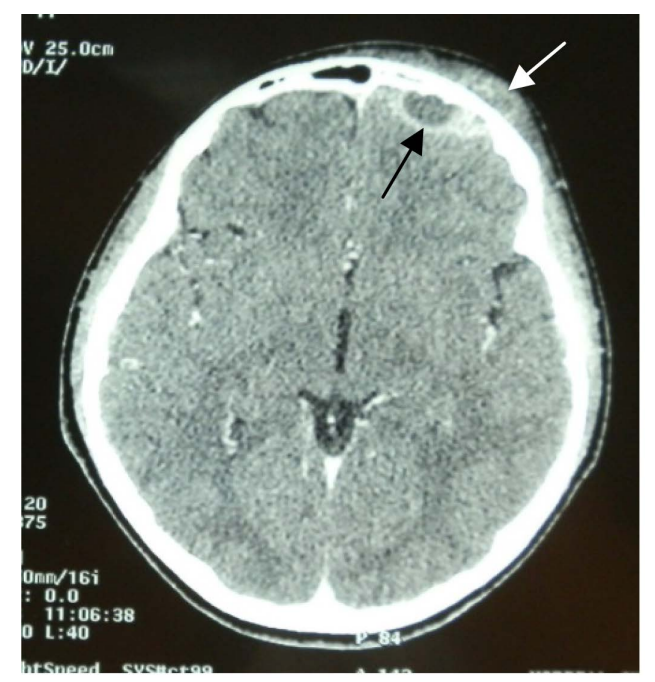

Figure 6. (Axial CT): Extradural empyema of the frontal lobe with Pott's puffy tumor.

thrombophlebitis was noted in 4 cases.

Imaging data are summarized in Table 3.

Antibiotics were administered in all cases (Table 4). Anticonvulsant treatment was administered in 10 cases, associated with corticosteroids in 3 cases. Heparin therapy was administrated to the 4 patients having cerebral thrombophlebitis.

Three patients with extradural empyema underwent exclusive medical treatment. Drainage was not indicated because of the limited size of the collection on imaging and the good evolution under antibiotics.

All other patients (20 cases) were operated. One patient had Pott's Puffy tumor and sinus drainage, without drainage of an associated limited extradural empyema. In 19 cases, intracranial collection was evacuated by trepanation or by making a frontal bone flap. Among these, a Pott's Puffy tumor drainage was associated in 7 cases and an orbital drainage in 4 cases.

Regarding the sinuses, surgery was performed in 20 cases. Drainage through Jacques approach (or frontosuperciliary approach) was performed in 6 cases. Three patients underwent endonasal surgery (bilateral ethmoidectomy). Frontal sinus cranialization was performed in 11 cases. It was indicated because of osteitis of the posterior table. To perform cranialization, bicoronal approach was used (called Cairns-Unterberger approach), with making a frontal flap, resection of the frontal sinus mucosa and of the osteitic foci of both anterior and posterior table (Figure 7). Closure of the naso-frontal canal was very important to avoid any recurrences. It was ensured with muscular fragments. The act ended with the replacement of the frontal bone flap and the lowering 
Table 3. Imaging data.

\begin{tabular}{cc}
\hline Imaging data & Number of cases \\
\hline Sinus & \\
filling & 23 \\
osteitis & 13 \\
subperiostal abcess & 8 \\
Orbit & \\
cellulitis & 2 \\
subperiostal abcess & 2 \\
orbital abcess & 2 \\
Endocranium & \\
subdural empyema & 11 \\
extradural empyema & 7 \\
cerebral abscess & 5 \\
cerebral thrombophlebitis & 4 \\
\hline
\end{tabular}

Table 4. Antibiotic therapy administrated intravenously.

\begin{tabular}{|c|c|}
\hline Molecules & Number of cases \\
\hline $3^{\text {rd }}$ GC + Ciprofloxacin + Metronidazole & 5 \\
\hline $3^{\text {rd }}$ GC + Ciprofloxacin + Metronidazole + Aminoglyoside & 4 \\
\hline $3^{\text {rd }} \mathrm{GC}+$ Fosfomycin + Metronidazole & 4 \\
\hline $3^{\text {rd }} \mathrm{GC}+$ Fosfomycin + Metronidazole + Aminoglyoside & 3 \\
\hline $3^{\text {rd }}$ GC + Metronidazole + Aminoglyoside & 3 \\
\hline $3^{\text {rd }} \mathrm{GC}+$ Fosfomycin + Aminoglyoside & 1 \\
\hline Ciprofloxacin + Fosfomycin & 1 \\
\hline Ciprofloxacin + Vancomycin & 1 \\
\hline Ciprofloxacin + Vancomycin + Metronidazole & 1 \\
\hline
\end{tabular}

$3^{\text {rd }}$ GC: Third generation cephalosporin

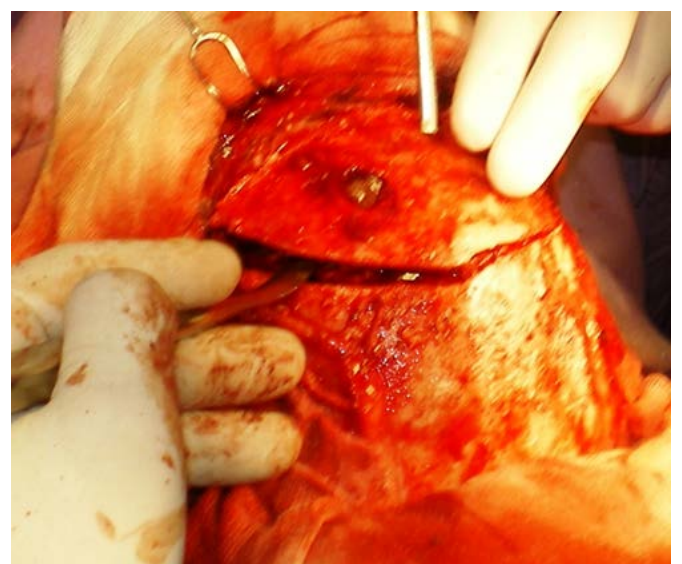

Figure 7. Making of a frontal bone flap after bicoronal approach.

and the suture of the skin flap.

The outcome after treatment was favorable in 14 cases (60.8\%) with regression of functional symptoms and disappearance of intracranial collection. One patient operated for brain abscess has died in the postoperative period despite intensive care. On the other hand, we noted in 8 cases a persistent or a worsening of the neurological signs. This non improvement was due to a recurrence or persistence of empyema (6 cases, of which one has 
already undergone cranialization) and the appearance of encephalitis and cerebral thrombophlebitis (2 cases). For all of them, antibiotherapy was prolonged to 10 weeks. Six patients (among the 8) underwent neurosurgical drainage, associated with frontal sinus cranialization in 3 cases. Among these patients, evolution was favorable in 7 cases, and one patient has died 3 days after surgery because of multiple organ dysfunction syndrome secondary to a septic shock.

Among all patients who have healed, no recurrence was noted after long-term follow-up.

\section{Discussion}

The frontal sinus is most commonly involved in intracranial complications of sinusitis, either alone or with an associated anterior ethmoiditis or pansinusitis [2] [3]. Intracranial complications of isolated posterior ethmoid sinusitis or sphenoiditis are rare [1] [4]. Cases of cavernous sinus thrombophlebitis often complicate acute sphenoiditis.

These complications usually involve young subjects between 20 and 30 years, mainly male [1] [2] [5]-[7]. These epidemiological data are consistent with those of our series. Regarding the incidence, reference centers in developed countries report an average of three cases per year [1]. In our series, more than 2/3 of patients were collected during the first 6 years of the study. Major risk factors reported in the literature are diabetes, immunesuppression, renal failure, history of facial trauma or inadequate previous treatment [1] [2]. Other contributing factors are reported, such as history of chronic sinusitis which acts through a greater resistance to antibiotics (induced by repeated treatments) and through a less penetration of the antibiotic secondary to osteo-mucosal modifications [1] [2]. Aerobic bacteria are those found in acute sinusitis: Haemophilus influenzae, Streptococcus and Staphylococcus [1] [8].

The revelation mode of intracranial complications of sinusitis is very variable. Headache is the most common and the most constant sign (100\% in our series). It reflects the frontal sinusitis and also the presence of intracranial hypertension. Its evolution in 2 stages (localized to the sinus then diffuse) is highly suggestive [1]. Other suggestive signs include frontal syndrome, meningeal syndrome, consciousness disorders and seizures [1] [9]-[11]. Rarely, intracranial complications can be latent or have nonspecific signs. Fever is present in 50\% - 58\% of cases [8].

Sinonasal and cerebral CT with iodine contrast media injection is necessary to confirm the diagnosis. When meningitis is suspected, CT is essential before performing the lumbar puncture, in order to avoid the risk of cerebral herniation [1] [12]. CT must always be performed in case of unfavorable evolution.

CT allows to visualize the sinus involved, to identify the type of complication (empyema, abscess, thrombophlebitis) and its site (often frontal, rarely frontoparietal or multiple) [13]. The presence of a subperiosteal abscess (Pott's puffy tumor) or of orbital complications (cellulitis, abscess) is correlated with an increased risk of intracranial complications [1] [5]. MRI can better assess intracranial extension [14] [15], but it is rarely performed in emergency situations. The most common complications found are subdural empyema (35\%), intracranial abscess (31\%) and meningitis (25\%). Multiple complications are not rare (25\% of cases). In our series, the subdural empyema was the most common complication (47.8\%).

Since intracranial extension of sinusitis can be a life-threatening complication, treatment should be aggressive from the beginning [1] [5] [7] [16] [17]. Medical treatment should be initiated precociously as soon as possible. The empirical antibiotic therapy essentially aims gram positive cocci, gram negative bacilli and anaerobic germs. Third-generation cephalosporins, fluoroquinolones, aminoglycosides, metronidazole and antistaphylococcals are recommended. This antibiotic therapy must secondarily be adapted to the antibiogram. Its duration is usually 4 to 8 weeks, in which 2 to 3 weeks intravenously [18]. In our study, given the frequent negativity of bacteriological samples, probabilistic antibiotic therapy was administrated in most cases.

The use of corticosteroids for its anti-edematous effect is controversial because of the risk of infection exacerbation. Currently, the treatment is indicated only in cases of life-threatening intracranial hypertension and cerebral edema [1] [19]-[21]. Anticonvulsants are usually recommended prophylactically in all cases of intracranial collection [1] [19]. Some authors recommend them only after a first seizure or after surgery [10]. In our series, they have been used in cases of severe peri-lesional edema with mass effect because of increased seizure risk.

On the other hand, the place of anticoagulation in cavernous sinus thrombophlebitis is discussed. Anticoagulant therapy has for a long time been considered dangerous because of the risk of bleeding. Currently, it has been 
demonstrated that anticoagulants reduce morbidities such as blindness, ophthalmoplegia, hypopituitarism, epilepsy and stroke. For some authors, heparin is routinely prescribed and relayed by antivitamin K for 6 weeks until repermeabilisation of the cavernous sinus [1].

The treatment of extra and subdural empyemas is neurosurgical drainage. Some series have shown the efficacy of single antibiotic treatment for some carefully selected cases of extradural empyema (with no neurological deficit, having limited purulent collection on CT, and with rapid clinical improvement under antibiotics) [22]. In our series, exclusive medical treatment was sufficient in 3 patients with extradural empyema.

Surgical treatment of intra-parenchymal abscess includes two methods: resection and puncture. Currently, puncture is preferred because of the low risk of contamination and of adjacent damage. Small abscesses less than $2 \mathrm{~cm}$ with a good neurological condition can be treated conservatively with antibiotics alone [1] [9] [12] [19] [22].

Treatment of the frontal sinus and of the possibly associated osteomyelitis represents an essential part of the therapeutic management. It helps to eliminate the causal lesion and therefore to avoid any source of treatment failure or relapse of intracranial complications. It is often performed at the same time of endocranial drainage and should be as simple and as minimalist as possible [1].

For drainage of the frontal sinus, we can perform either trephination (by drilling or by using Lemoyne nail) or a bone flap through Jacques approach. Frontal sinus can be also drained endoscopically by performing the Draf techniques. For the ethmoid and sphenoid, endoscopic ethmoidectomy and sphenoidotomy can be performed [1] [4]. Endonasal surgery was performed in 3 cases of our series. The limitation of this technique is that in can increase, in these inflammatory conditions, the risk of bleeding immediately and synechia in the long term. On the other hand, incomplete gesture in endonasal surgery would compromise the ventilation of the sinuses in some cases [1] [8] [23].

If the previous drainage techniques fail or if osteitis is extended or reaches the posterior table, then exclusion of the frontal sinus should be considered [24] [25]. Two different approaches are possible:

- Filling of the frontal sinus when there is an extended osteitis of the anterior table: after bicoronal approach, we perform a bone flap and resect the osteitic foci, then we carefully remove the entire sinus mucosa. Then we fill the sinus with muscles and we close the nasofrontal ostium. Some authors realize this filling under endoscopic control after Jacques approach [26]. This is a less invasive approach and as effective as the conventional approach [26].

- Neurosurgical exclusion (called also cranialization) of the frontal sinus [27]: after bicoronal approach and making a bone flap, we remove the mucosa and the posterior table, and we obturate the nasofrontal canal. This technique is indicated for internal table osteitis [27]-[29]. It is the most appropriate technique in cases of intracranial complications of sinusitis, treating both the collection and its origin. In our series, this technique was performed as first line treatment in 11 patients.

The prognosis of intracranial complications of sinusitis depends heavily on the nature of neurological signs and on the diagnosis and management delay of time [1] [30] [31]. The average rate of neurological sequelae is $23 \%$ on all the studied series. The average mortality rate is $6 \%$ [8]. Morbidity and mortality are lower in the pediatric population [32]. Complications and deaths are related to cortical veins thrombosis and to cerebral infarction. In our series, 2 patients have died (8.7\%).

\section{Conclusion}

Although rare, intracranial complications of sinusitis are severe and are source of high morbidity and mortality. They require multidisciplinary approach including otorhinolaryngologists, neurosurgeons and intensive care physicians. Management should be rapid and adequate, combining effective antibiotic therapy and eventually neurosurgical treatment.

\section{Conflict of Interest}

There are no conflicts of interest.

\section{References}

[1] Bayonne, E., El Bakkouri, W., Kania, R., Sauvaget, E., Tran Ba Huy, P. and Herman, P. (2007) Cranical and Endocranial 
Complications of Sinonasal Infections. EMC-Oto-Rhino-Laryngologie, 2, 20-445-A-10. http://dx.doi.org/10.1016/S0246-0351(07)41895-5

[2] Jones, N.S., Walker, J.L., Bassi, S., Jones, T. and Punt, J. (2002) The Intracranial Complications of Rhinosinusitis: Can They Be Prevented? The Laryngoscope, 112, 59-63. http://dx.doi.org/10.1097/00005537-200201000-00011

[3] Kombogiorgas, D., Seth, R., Athwal, R., Modha, J. and Singh, J. (2007) Suppurative Intracranial Complications of Sinusitis in Adolescence. Single Institute Experience and Review of Literature. British Journal of Neurosurgery, 21, 603609. http://dx.doi.org/10.1080/02688690701552856

[4] Poulopoulos, M. and Finelli, P.F. (2007) Neurological Complications with Acute Sphenoid Sinusitis a Surgical Emergency? Neurocritical Care, 7, 169-171. http://dx.doi.org/10.1007/s12028-007-0036-6

[5] Germiller, J.A., Monin, D.L., Sparano, A.M. and Tom, L.W. (2006) Intracranial Complications of Sinusitis in Children and Adolescents and Their Outcomes. Archives of Otolaryngology-Head \& Neck Surgery, 132, 969-976. http://dx.doi.org/10.1001/archotol.132.9.969

[6] Bair-Merritt, M.H., Shah, S.S., Zaoutis, T.E., Bell, L.M. and Feudtner, C. (2005) Suppurative Intracranial Complications of Sinusitis in Previously Healthy Children. Pediatric Infectious Disease Journal, 24, 384-386. http://dx.doi.org/10.1097/01.inf.0000160589.40857.ad

[7] Ong, Y.K. and Tan, H.K. (2002) Suppurative Intracranial Complications of Sinusitis in Children. International Journal of Pediatric Otorhinolaryngology, 66, 49-54. http://dx.doi.org/10.1016/S0165-5876(02)00209-4

[8] Fenton, J.E., Smyth, D.A., Viani, L.G. and Walsh, M.A. (1999) Sinogenic Brain Abscess. American Journal of Rhinology, 13, 299-302. http://dx.doi.org/10.2500/105065899782102854

[9] Sáez-Llorens, X. (2003) Brain Abscess in Children. Seminars in Pediatric Infectious Diseases, 14, 108-114. http://dx.doi.org/10.1053/spid.2003.127227

[10] Passeron, H., Sidy, Ka A., Diakhaté, I. and Imbert, P. (2010) Intracranial Suppurations of Otorhinolaryngological Origin in Children in Senegal. Archives de Pédiatrie, 17, 132-140. http://dx.doi.org/10.1016/j.arcped.2009.11.001

[11] Soumaré, M., Seydi, M., Ndour, C.T., Fall, N., Dieng, Y., Sow, A.I., et al. (2005) Epidemiological, Clinical, Etiological Features of Neuromeningeal Diseases at the Fann Hospital Infectious Diseases Clinic, Dakar (Senegal). Médecine et Maladies Infectieuses, 35, 383-389. http://dx.doi.org/10.1016/j.medmal.2005.03.009

[12] Harli, J.R., Vincentelli, F., Peragut, J.C., Weiller, P.J. and Grisoli, F. (1988) Brain Abscesses: Analysis of 41 Cases in Ten Years. Revue de Médecine Interne, 9, 369-376.

[13] Hoxworth, J.M. and Glastonbury, C.M. (2010) Orbital and Intracranial Complications of Acute Sinusitis. Neuroimaging Clinics of North America, 20, 511-526. http://dx.doi.org/10.1016/j.nic.2010.07.004

[14] Blumfield, E. and Misra, M. (2011) Pott’s Puffy Tumor, Intracranial, and Orbital Complications as the Initial Presentation of Sinusitis in Healthy Adolescents, a Case Series. Emergency Radiology, 18, 203-210. http://dx.doi.org/10.1007/s10140-010-0934-3

[15] Younis, R.T., Anand, V.K. and Davidson, B. (2002) The Role of Computed Tomography and Magnetic Resonance Imaging in Patients with Sinusitis with Complications. The Laryngoscope, 112, 224-229. http://dx.doi.org/10.1097/00005537-200202000-00005

[16] Hicks, C.W., Weber, J.G., Reid, J.R. and Moodley, M. (2011) Identifying and Managing Intracranial Complications of Sinusitis in Children: A Retrospective Series. The Pediatric Infectious Disease Journal, 30, 222-226. http://dx.doi.org/10.1097/INF.0b013e3181f86398

[17] Goldberg, A.N., Oroszlan, G. and Anderson, T.D. (2001) Complications of Frontal Sinusitis and Their Management. Otolaryngologic Clinics of North America, 34, 211-225. http://dx.doi.org/10.1016/S0030-6665(05)70307-8

[18] Glickstein, J.S., Chandra, R.K. and Thompson, J.W. (2006) Intracranial Complications of Pediatric Sinusitis. Otolaryngology—Head and Neck Surgery, 134, 733-736. http://dx.doi.org/10.1016/j.otohns.2005.12.001

[19] Gilain, L. and Manipoud, P. (1995) Cranial and Endocranial Complications of Sinonasal Infections. Traité d’OtorhinoLaryngologie, 445, A10.

[20] Lemarchand, E., Letouze, S., Du Manoir, B., Courthéoux, P., Bricard, H. and Gérard, J.L. (2003) Severe Cerebral Thrombophlebitis: Can We Fibrinolyse ? Annales Françaises d'Anesthésie et de Réanimation, 22, 133-136. http://dx.doi.org/10.1016/S0750-7658(02)00862-6

[21] Jones, H., Trinidade, A., Jaberoo, M.C. and Lyons, M. (2012) Periorbital Cellulitis, Subgaleal Abscess and Superior Sagittal Sinus Thrombosis: A Rare Combination of Complications Arising from Unilateral Frontal Sinusitis. The Journal of Laryngology \& Otology, 126, 1281-1283. http://dx.doi.org/10.1017/s0022215112002228

[22] Emery, E., Redondo, A., Berthelot, J.L., Bouali, I., Ouahes, O. and Rey, A. (1999) Intracranial Abscesses and Empyemas: Neurosurgical Management. Annales Françaises d'Anesthésie et de Réanimation, 18, 567-573. http://dx.doi.org/10.1016/S0750-7658(99)80134-8 
[23] Del Gaudio, J.M., Evans, S.H., Sobol, S.E. and Parikh, S.L. (2010) Intracranial Complications of Sinusitis: What Is the Role of Endoscopic Sinus Surgery in the Acute Setting? American Journal of Otolaryngology, 31, 25-28. http://dx.doi.org/10.1016/j.amjoto.2008.09.009

[24] Lee, J.J. and Jacobs, J.B. (2001) Frontal Sinusitis. Operative Techniques in Otolaryngology—Head and Neck Surgery, 12, 80-82. http://dx.doi.org/10.1053/otot.2001.23728

[25] Soyka, M.B., Annen, A. and Holzmann, D. (2009) Where Endoscopy Fails: Indications and Experience with the Frontal Sinus Fat Obliteration. Rhinology, 47, 136-140.

[26] Ung, F., Sindwani, R. and Metson, R. (2005) Endoscopic Frontal Sinus Obliteration: A New Technique for the Treatment of Chronic Frontal Sinusitis. Otolaryngology_Head and Neck Surgery, 133, 551-555. http://dx.doi.org/10.1016/j.otohns.2005.06.014

[27] Ameline, E., Wagner, I., Delbove, H., Coquille, F., Visot, A. and Chabolle, F. (2001) Cranialization of the Frontal Sinus. Annales d'oto-laryngologie et de chirurgie cervico faciale, 118, 352-358.

[28] Constantinidis, J., Weber, R., Brune, M., Draf, W. and Iro, M. (2000) Cranialisation of the Frontal Sinus: Indications, Technique and Results. HNO, 48, 361-366.

[29] Altman, K.W., Austin, M.B., Tom, L.W.C. and Knox, G.W. (1997) Complications of Frontal Sinusitis in Adolescents: Case Presentations and Treatment Options. International Journal of Pediatric Otorhinolaryngology, 41, 9-20. http://dx.doi.org/10.1016/S0165-5876(97)00047-5

[30] Betz, C.S., Issing, W., Matschke, J., Kremer, A., Uhl, E. and Leunig, A. (2008) Complications of Acute Frontal Sinusitis: A Retrospective Study. European Archives of Oto-Rhino-Laryngology, 265, 63-72. http://dx.doi.org/10.1007/s00405-007-0411-0

[31] Osborn, M.K. and Steinberg, J.P. (2007) Subdural Empyema and Other Suppurative Complications of Paranasal Sinusitis. The Lancet Infectious Diseases, 7, 62-67. http://dx.doi.org/10.1016/S1473-3099(06)70688-0

[32] Giannoni, C., Sulek, M. and Friedman, E.M. (1998) Intracranial Complications of Sinusitis: A Pediatric Series. The American Journal of Rhinology, 12, 173-178. 